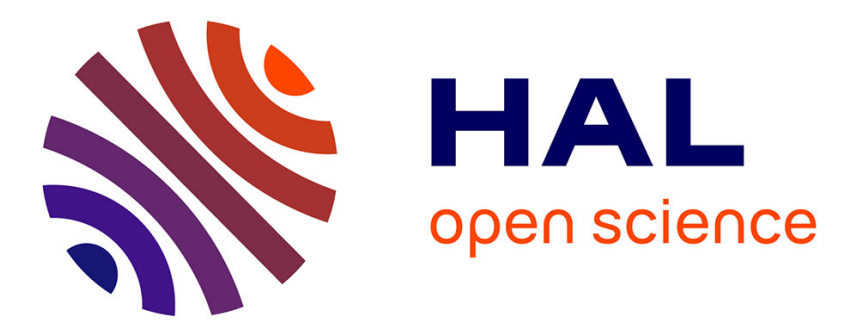

\title{
Atom redistribution during co-doped amorphous silicon crystallization
}

\author{
A. Portavoce, D. Mangelinck, R Simola, R Daineche, J. Bernardini
}

\section{To cite this version:}

A. Portavoce, D. Mangelinck, R Simola, R Daineche, J. Bernardini. Atom redistribution during co-doped amorphous silicon crystallization. Defect and Diffusion Forum, 2009, 289-292, pp.329-337. hal-02406667

\section{HAL Id: hal-02406667 https://hal-amu.archives-ouvertes.fr/hal-02406667}

Submitted on 12 Dec 2019

HAL is a multi-disciplinary open access archive for the deposit and dissemination of scientific research documents, whether they are published or not. The documents may come from teaching and research institutions in France or abroad, or from public or private research centers.
L'archive ouverte pluridisciplinaire HAL, est destinée au dépôt et à la diffusion de documents scientifiques de niveau recherche, publiés ou non, émanant des établissements d'enseignement et de recherche français ou étrangers, des laboratoires publics ou privés. 


\title{
Atom redistribution during co-doped amorphous silicon crystallization
}

\author{
A. Portavoce ${ }^{1,2, a}$, D. Mangelinck ${ }^{1,2, b}$, R. Simola ${ }^{3, c}$, R. Daineche $e^{1, d}$ \\ and J. Bernardini ${ }^{1,2, e}$ \\ ${ }^{1}$ Aix-Marseille Université, IM2NP
}

${ }^{2}$ CNRS, IM2NP (UMR 6242) Faculté des Sciences et Techniques, Campus de Saint-Jérôme

Avenue Escadrille Normandie Niemen - Case 142, F-13397 Marseille Cedex, France

${ }^{3}$ ST Microelectronics, 77 Avenue Olivier Perroy, 13790 Rousset, France

aalain.portavoce@l2mp.fr, bdominique.mangelinck@l2mp.fr, 'roberto.simola@st.com, rachid.daineche@I2mp.fr, ${ }^{\mathrm{d}}$ jean.bernardini@I2mp.fr

Keywords: Silicon crystallization, boron, phosphorus, diffusion, dopant interactions.

\begin{abstract}
Atom redistribution during crystallization of a $\mathrm{B}$ and $\mathrm{P}$ co-doped amorphous Si layer produced by $\mathrm{Si}$ and $\mathrm{P}$ chemical vapor co-deposition and $\mathrm{B}$ implantation has been investigated. The crystallization of the entire layer is quasi-instantaneous for annealing temperature greater than $650{ }^{\circ} \mathrm{C}$. The crystallization rate is well reproduced by the Avrami-Johnson-Mehl-Kolmogorov model of transformation. The Avrami $\mathrm{n}$ is found equal to 4, which is corresponding to 3D bulk crystallization. Crystallization promotes a non-Fickian redistribution of $\mathrm{B}$ atoms, allowing for an abrupt interface between B-doped and B-undoped regions. After crystallization, B diffuses in the polycrystalline Si layer for concentrations lower than $1.5 \times 10^{20}$ at $\mathrm{cm}^{-3}$ via the type $B$ kinetic regime. Crystallization has no significant (or detectable) influence on the $\mathrm{P}$ profile. For temperatures higher than $750{ }^{\circ} \mathrm{C}$, $\mathrm{P}$ diffuses in the poly-Si layer towards the region of highest $\mathrm{B}$ concentration via the type $B$ kinetic regime, leading to $\mathrm{P}$ uphill diffusion. This phenomenon can be simulated considering chemical interactions between $\mathrm{B}$ and $\mathrm{P}$ atoms in both grains and grain boundaries.
\end{abstract}

\section{Introduction}

The creation of abrupt $p n$-junctions in polycrystalline $\mathrm{Si}$ (poly-Si) is necessary for different applications, as for thin film solar cell [1-2] and advanced floating-gate memory [3] fabrication. One method of production consists of implanting $p$-type dopants in a $n$-type amorphous Si layer before crystallization via thermal treatments. This process involves several redistribution phenomena: during crystallization, dopants can migrate in the amorphous regions and in the growing grains, while at the end of the crystallization dopants migrate in a poly-Si layer. Furthermore, crystallization may involve a dopant redistribution different than the diffusion phenomenon due to a partition effect between the amorphous and the crystalline phases. It is of major importance to understand the redistribution of dopants during this process in order to create and improve the characteristics of the $p n$-junction. Since the solid phase epitaxy regrowth (SPER) technique appears to be a very promising doping process [4-6], crystallization of amorphized doped-Si is still currently investigated [7-11]. For example, theoretical [8] and experimental [7,9] works concerning $\mathrm{B}$-doped $\mathrm{Si}$ crystallization have been recently published. Nevertheless the crystallization of co-doped amorphous Si has been less investigated.

This article focuses on the redistribution of $\mathrm{B}$ ( $p$-type dopant) and $\mathrm{P}$ ( $n$-type dopant) atoms, which are commonly used to create $p n$-junctions in the microelectronic Si technology, during crystallization of a co-doped amorphous $\mathrm{Si}(\mathrm{a}-\mathrm{Si})$ layer. The layer crystallization is shown to follow the Avrami-Johnson-Mehl-Kolmogorov (AJMK) model of transformation. The crystallization modifies the initial $\mathrm{B}$ distribution, but does not modify the initial $\mathrm{P}$ distribution. After 
crystallization, for annealing temperatures greater than $750{ }^{\circ} \mathrm{C}, \mathrm{P}$ uphill diffusion is observed. This phenomenon can be simulated considering P-B chemical interactions.

\section{Experimental}

Two types of samples have been grown. Each sample was made of a P-doped amorphous $\mathrm{Si}$ (a-Si) layer deposited on a $12 \mathrm{~nm}$-thick $\mathrm{SiO}_{2}$ layer thermally grown on a $\mathrm{Si}(001)$ wafer. The a-Si layer was homogenously doped in situ with $\mathrm{P}$ atoms $\left(\sim 7 \times 10^{19}\right.$ at $\left.\mathrm{cm}^{-3}\right)$ thanks to the simultaneous injection of phosphine and silane gases in the growth chamber during low pressure chemical vapor deposition (LPCVD) at $530{ }^{\circ} \mathrm{C}$. After LPCVD growth, a dose of $\sim 3.5 \times 10^{15} \mathrm{~B}$ atoms cm ${ }^{-2}$ was implanted in the a-Si layer with an implantation energy of $7 \mathrm{keV}$. The sample was then cut into several pieces for analyzes. The thickness of the co-doped a-Si layer was $150 \mathrm{~nm}$ for the first sample used in the crystallization study, and $100 \mathrm{~nm}$ for the second sample used in the diffusion study.

All the samples were annealed under a vacuum of $\sim 1 \times 10^{-6}$ Torr. In order to study the crystallization of the co-doped a-Si layer, samples were annealed at constant temperature $(550 \leq \mathrm{T} \leq$ $600{ }^{\circ} \mathrm{C}$ ) during in situ X-ray diffraction (XRD) measurements. The intensity of the $\operatorname{Si}(111)$ diffraction peak which is proportional to the crystallized fraction of the layer was recorded in real time during the isothermal annealing. Other samples were studied ex situ by transmission electron microscopy (TEM) and atomic force microscopy (AFM) after annealing $\left(550 \leq \mathrm{T} \leq 800^{\circ} \mathrm{C}\right)$.

For the diffusion study, one piece of sample was kept as a reference and the others were annealed at different temperatures $\left(585 \leq \mathrm{T} \leq 800^{\circ} \mathrm{C}\right)$. After the thermal treatments, the $\mathrm{B}$ and the $\mathrm{P}$ concentration profiles versus the sample depth were measured by secondary ion mass spectroscopy (SIMS) using a primary ion beam of $\mathrm{O}_{2}{ }^{+}$ions with an energy of $3 \mathrm{keV}$. The $\mathrm{B}$ profiles were measured under vacuum with a primary ion beam angle of $45^{\circ}$, while the $\mathrm{P}$ profiles were measured under oxygen ambient (oxygen leak) with an incident beam angle of $25.2^{\circ}$.

\section{Results and Discussion}

Co-doped Silicon Crystallization. Figure 1 presents the variation of the Si(111) XRD peak intensity measured versus time $(\mathrm{t})$ during sample annealing at three different temperatures: 546, 561 and $583{ }^{\circ} \mathrm{C}$.

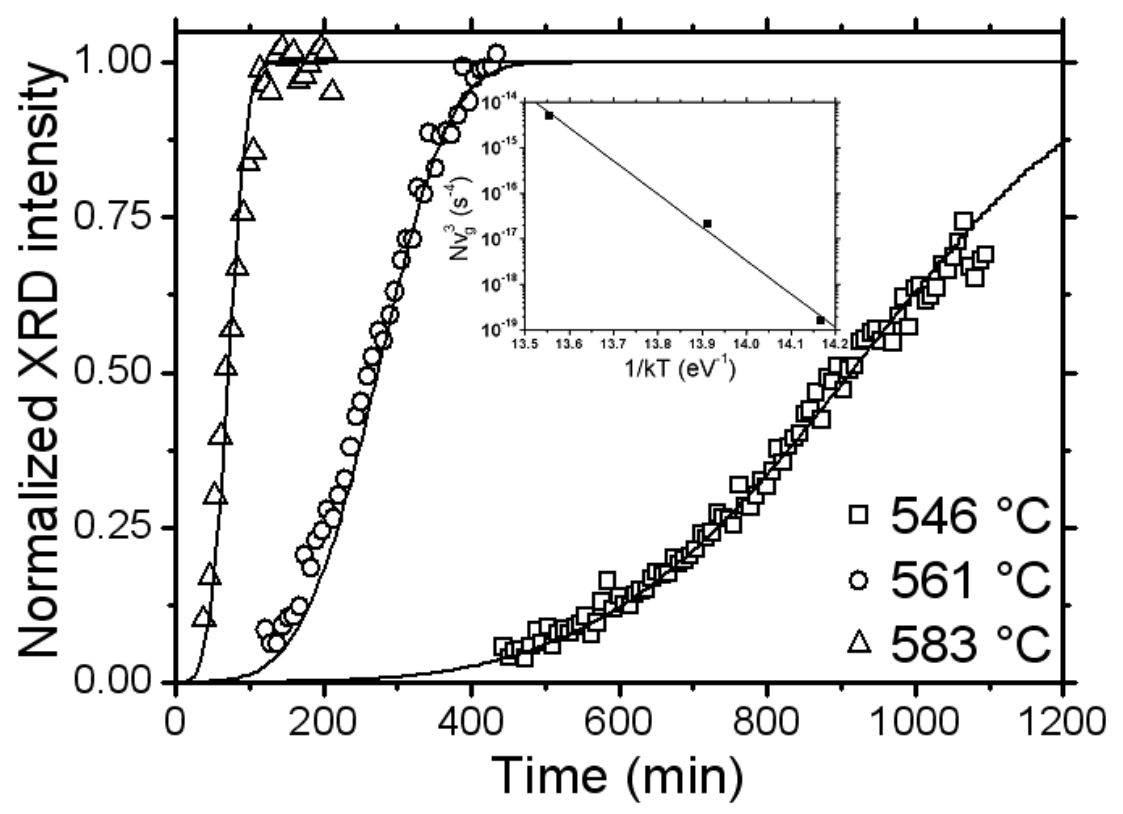

Fig. 1. Variation of the normalized intensity of the $\operatorname{Si}(111)$ diffraction peak measured by XRD (open symbols) during in situ annealing of a $150 \mathrm{~nm}$-thick P and B co-doped aSi layer. The solid lines correspond to the AJMK law with an Avrami $\mathrm{n}=4$. The insert presents the logarithmic variation of the $N v_{g}^{3}$ $\left(\mathrm{s}^{-4}\right)$ term of the AJMK model for $3 \mathrm{D}$ growth versus $1 / \mathrm{kT}\left(\mathrm{eV}^{-1}\right)$. The solid line corresponds to the fit allowing for the measurement of the total activation energy $E_{C}$ of crystallization.

The XRD intensity is proportional to the volume fraction of the layer which is crystalline. Initially, the XRD intensity is zero since the layer is totally amorphous. When the normalized XRD intensity 
reaches 1 the totality of the layer is polycrystalline. For the 3 different annealing temperatures, when the $\operatorname{Si}(111)$ peak is first detected, the transformed volume is about the same. The time $\tau$ which corresponds to the first detection, is proportional to the time needed for nucleation of the first $\mathrm{Si}$ grains in the amorphous matrix. One can see that the nucleation time decreases when the temperature increases. It follows an Arrhenius law of the temperature with an activation energy $Q \sim$ $3.98 \pm 0.5 \mathrm{eV}$. Following the Avrami-Johnson-Mehl-Kolmogorov model [10], considering that at a given temperature the nucleation rate $(N)$ and the growth rate $\left(v_{g}\right)$ are constant, the crystallized fraction $f$ can be expressed as:

$$
f=1-\exp \left(-\alpha t^{n}\right)
$$

$\alpha$ is a constant and $\mathrm{n}$ is the Avrami exponent also called "the Avrami $\mathrm{n}$ ". The value of $\mathrm{n}$ is related to the dimensions of the growth. $\mathrm{n}$ is comprised between 1 and 2 for 1D growth (wire), between 2 and 3 for 2D growth (film), and between 3 and 4 for 3D growth (grain). The best fits of the XRD measurements occur for $\mathrm{n} \sim 4$ that corresponds to $3 \mathrm{D}$ growth, the fits are presented in fig. 1 in solid lines.

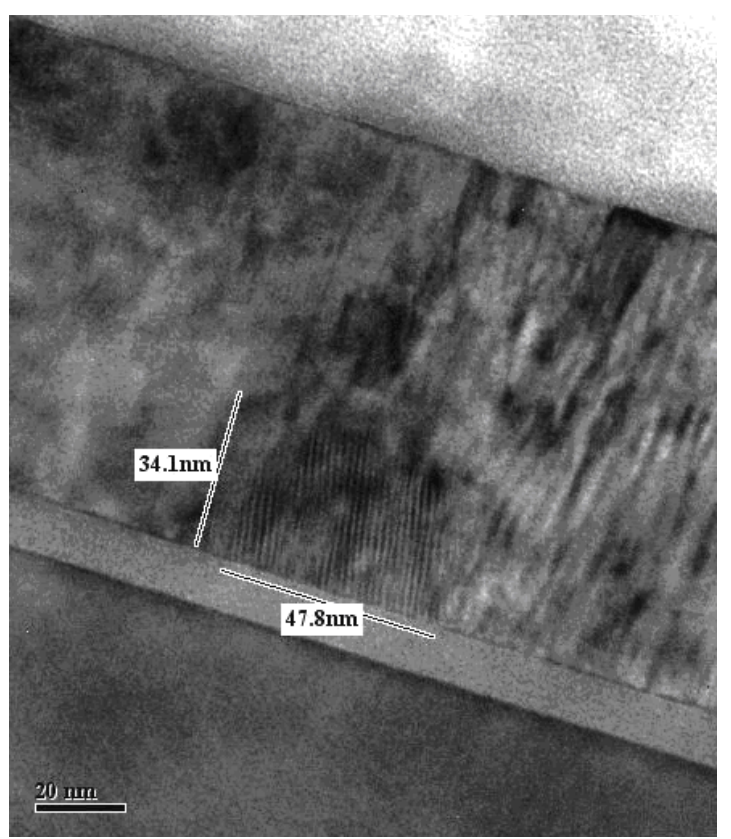

Fig. 2. High resolution TEM image in cross-section obtained after annealing the sample at $800{ }^{\circ} \mathrm{C}$ for 5 hours. The orientation of the sample allows to observe atomic plans in a Si grain. The scale bar is $20 \mathrm{~nm}$.

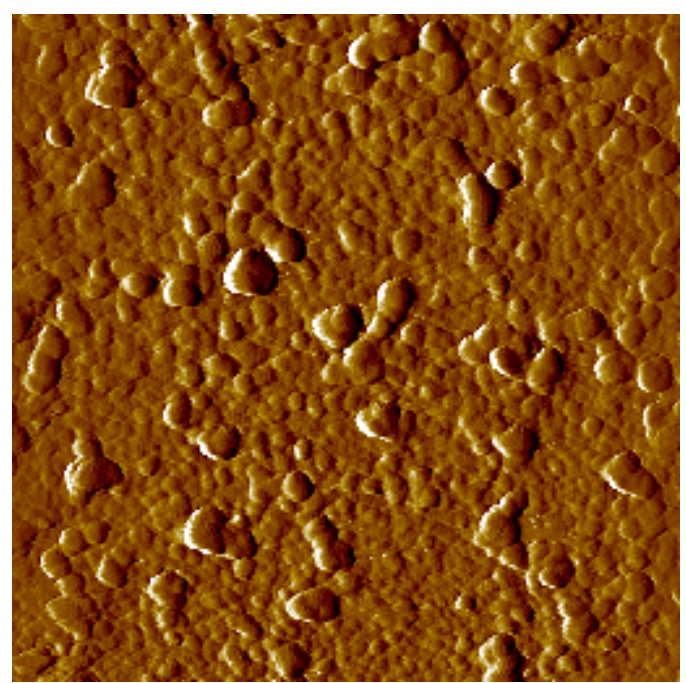

Fig. 3. AFM image obtained on the surface of a sample annealed at $700{ }^{\circ} \mathrm{C}$ for 6 hours, after a chemical treatment allowing for the observation of the grain boundaries. The image is $1 \times 1 \mu \mathrm{m}^{2}$.

The 3D character of the growth of the crystalline fraction has been also confirmed by TEM, since Si grains are easily observed in the TEM images of the crystallized layers (fig.2). In the general case of growth of spherical-shape grains, $\alpha$ can be written:

$$
\alpha=\frac{\pi}{3} N v_{g}^{n-1} \text { with } N=N_{0} \exp \left[-\frac{E_{n}}{k T}\right] \text { and } v_{g}=v_{0} \exp \left(-\frac{E_{g}}{k T}\right)
$$

$E_{n}$ and $E_{g}$ are the nucleation activation energy and the grain growth activation energy, respectively. $k$ is the Boltzmann constant. 
Considering that $\mathrm{n}=4$ and combining eqs. 1 and 2 we obtain:

$$
f=1-\exp \left[-\frac{\pi}{3} N_{0} v_{0}^{3} \exp \left(-\frac{E_{n}+3 E_{g}}{k T}\right) t^{4}\right] \text {. }
$$

The XRD measurements have been fitted using eq. 3 (fig. 1) in order to determine $E_{c}=E_{n}+3 E_{g}$. The $N v_{g}^{3}$ term extracted from our fitting procedure is presented versus $1 / \mathrm{kT}$ in the insert of fig. 1 . We obtained $E_{c} \sim 16.8 \pm 0.5 \mathrm{eV}$. This value is higher than the one measured by Farjas et al. [11] who found $E_{c} \sim 14.4 \pm 0.5 \mathrm{eV}$ for pure Si. Considering that $E_{n} \sim 5.3 \mathrm{eV}$ [11] we deduce $E_{g} \sim 3.83$ $\mathrm{eV}$. Nucleation and growth during $\mathrm{Si}$ crystallization depend on the nature of the impurities contained in the layer and their concentration [12-13], as well as on the method of production of the amorphous layer, for example Spinella et al. have shown that the crystallization kinetic is faster in non-implanted a-Si layers than in Si-implanted a-Si layers [14].

Post-annealing TEM (fig. 2) and AFM (fig. 3) measurements have shown that for temperatures between 600 and $800{ }^{\circ} \mathrm{C}$ the average lateral size of the $\mathrm{Si}$ grains is about $50 \pm 5 \mathrm{~nm}$. Figure 2 is a high resolution TEM image in cross-section view showing a grain with a lateral size of $\sim 47.8 \mathrm{~nm}$ and with a length along the layer thickness of $\sim 34.1 \mathrm{~nm}$. For AFM measurements, the samples were dipped $20 \mathrm{~s}$ in a $\mathrm{HF}: 0.04 / \mathrm{HNO}_{3}: 1 / \mathrm{H}_{2} \mathrm{O}: 1$ solution in order to reveal the grain boundaries. AFM allows an important statistic. For example, after annealing at $600{ }^{\circ} \mathrm{C}$ for 24 hours we observe 3 populations of grains with an average lateral size of $\sim 170,80$ and $50 \mathrm{~nm}$, and a density of $\sim 7 \times$ $10^{8}, 1.2 \times 10^{9}$ and $2.8 \times 10^{10} \mathrm{~cm}^{-2}$, respectively. Considering the difference of density of the 3 island populations, the average size of the grains after this thermal treatment is $\sim 54 \mathrm{~nm}$. After annealing at $700{ }^{\circ} \mathrm{C}$ for 6 hours, two island populations have been observed with an average lateral size of $\sim 80$ and $50 \mathrm{~nm}$, and a density of $\sim 1.4 \times 10^{9}$ and $3.6 \times 10^{10} \mathrm{~cm}^{-2}$, respectively (fig. 3 ). The total average lateral size of the grains is thus $\sim 51 \mathrm{~nm}$. After annealing at $800^{\circ} \mathrm{C}$ for 6 hours a single island population has been observed with an average lateral size of $\sim 45 \mathrm{~nm}$.

Boron Redistribution. The B SIMS profiles measured after annealing at $585^{\circ} \mathrm{C}$ for $1 \mathrm{~h}, 650{ }^{\circ} \mathrm{C}$ for 7.5 and $50.33 \mathrm{~h}, 793{ }^{\circ} \mathrm{C}$ for $3 \mathrm{~h}$, and $800{ }^{\circ} \mathrm{C}$ for $5 \mathrm{~h}$ are presented in figure 4 with the B profile measured just after implantation. Before crystallization the profile of $\mathrm{B}$ exhibits a Gaussian shape. The crystallization does not change significantly the B profile for depths less than $\sim 55 \mathrm{~nm}$, but causes the formation of a shoulder deeper in the sample with a depth penetration of $\sim 20 \mathrm{~nm}$ and a concentration of $\sim 1.5 \times 10^{20} \mathrm{at} \mathrm{cm}^{-3}$. This effect can be seen on the profile obtained after annealing at $585{ }^{\circ} \mathrm{C}$ for $1 \mathrm{~h}$ (fig. 4). This thermal treatment permitted the crystallization of the layer, but was not sufficient for B diffusion in the poly-Si layer. As a result, the interface between the B-doped and the B-undoped regions is abrupt, leading to a sharp $p n$-junction interface. For higher temperature and /or longer time annealing, the $\mathrm{B}$ distribution for depths less than $75 \mathrm{~nm}$ does not change notably, while $\mathrm{B}$ atoms with a concentration lower than $\sim 1.5 \times 10^{20}$ at $\mathrm{cm}^{-3}$ diffuse deeper in the poly-Si layer. The SIMS profiles measured after annealing at $793{ }^{\circ} \mathrm{C}$ for $3 \mathrm{~h}$ and at $800{ }^{\circ} \mathrm{C}$ for $5 \mathrm{~h}$ are almost identical (arrow on fig. 4), showing that a stationary B distribution has been reached. These observations leads to the conclusion that during crystallization B clusters or precipitates are formed in the sample regions having a B concentrations greater than the solubility limit, which appears to be about $2 \times 10^{20}$ at $\mathrm{cm}^{-3}$. The $\mathrm{B}$ atoms contained in these clusters are immobile. The clusters seem to be stable during annealing since beside a small decrease of concentration due to the diffusion of mobile B atoms, the shape of the B profile for depths less than $\sim 50 \mathrm{~nm}$ does not change (same Gaussian distribution). Simulations of the B diffusion in the crystallized Si layers support also this interpretation [15]. 


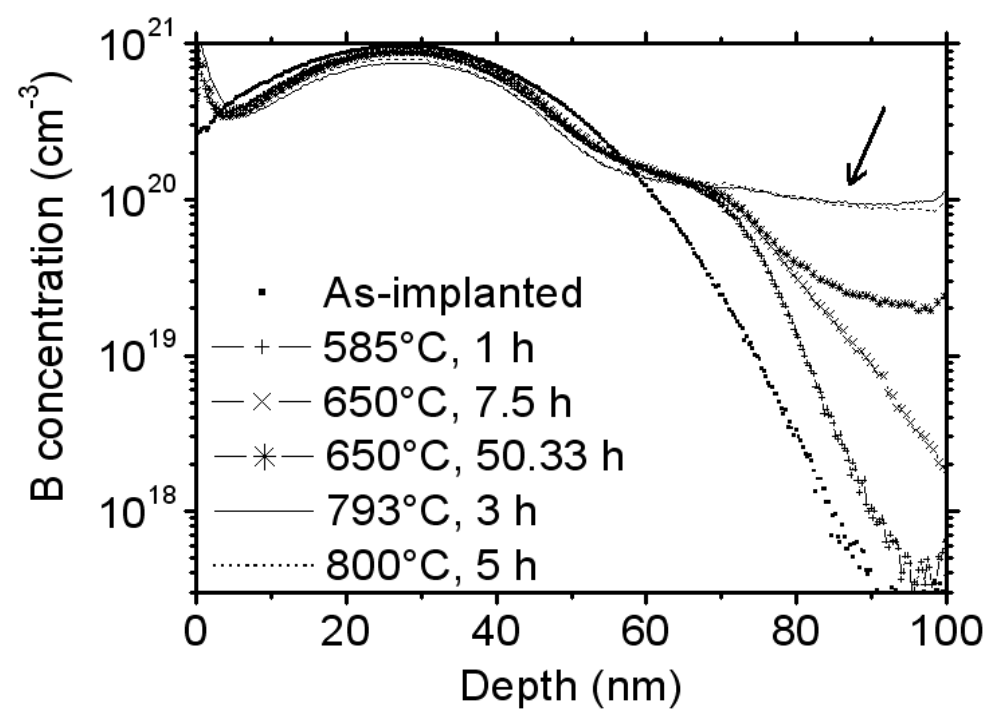

Fig. 4. SIMS profiles of B measured in the sample after different heat treatments.

The XRD measurements have shown that the crystallization occurs by 3D growth and thus does not follow a 2D growth with the displacement of a uniform Poly-Si /a-Si interface along the sample depth. Consequently, the shoulder-shape of the B redistribution can be more easily attributed to B diffusion in a-Si, than to a partition effect between the shrinking amorphous phase and the growing crystalline phase. Indeed, similar diffusion profiles have been observed in highly B concentrated a$\mathrm{Si}$ layers [16]. Once the crystallization is finished, B atoms diffuse in a poly-Si layer made of $\sim 50$ $\mathrm{nm}$ wide grains until that the concentration of mobile $\mathrm{B}$ atoms is the same in the whole sample. We have previously shown [15] that $B$ is diffusing via the type $B$ kinetic regime in the crystallized samples.

Phosphorus Redistribution. Figure 5 presents SIMS profiles measured in the as-grown sample and in samples annealed at $585{ }^{\circ} \mathrm{C}$ for $1 \mathrm{~h}$, at $793{ }^{\circ} \mathrm{C}$ for $3 \mathrm{~h}$, and at $800{ }^{\circ} \mathrm{C}$ for $5 \mathrm{~h}$. Comparing the $\mathrm{P}$ distribution in the as-grown sample with the $\mathrm{P}$ profile in the sample annealed at $585^{\circ} \mathrm{C}$ for 1 hour, one can see that the crystallization of the a-Si layer does not significantly modify the distribution of $\mathrm{P}$ atoms. After crystallization, we observe the diffusion of $\mathrm{P}$ atoms toward the region of the sample of high $\mathrm{B}$ concentration for temperatures greater than $750{ }^{\circ} \mathrm{C}$. At lower temperatures, the $\mathrm{P}$ atoms are immobile even if $\mathrm{B}$ is diffusing [15]. It is interesting to notice that for $\mathrm{T}>750{ }^{\circ} \mathrm{C}$ i) the initial gradient of concentration of $\mathrm{P}$ atoms cannot be the driving force of the $\mathrm{P}$ uphill diffusion, ii) the distribution of the mobile $\mathrm{P}$ atoms forms a Gaussian centered on the Gaussian distribution of the immobile B atoms (fig. 6), and iii) the comparison of the B and the P SIMS profiles in the samples annealed at $793{ }^{\circ} \mathrm{C}$ for $3 \mathrm{~h}$ and at $800{ }^{\circ} \mathrm{C}$ for $5 \mathrm{~h}$ shows that the $\mathrm{P}$ atoms keep on diffusing toward the region of the sample containing the $\mathrm{B}$ clusters (immobile $\mathrm{B}$ atoms) even if the concentration of mobile $\mathrm{B}$ atoms is homogeneous. The interactions between $\mathrm{P}$ and $\mathrm{B}$ atoms can be of two types: chemical and electrostatic. B and $\mathrm{P}$ are chemically attracted as these two elements are known to form binary compounds [17]. They are also forming binary compounds with Si [17]. Thus, because of the chemical interactions between the three elements $\mathrm{Si}, \mathrm{B}$, and $\mathrm{P}$, and the high concentration level of B and $\mathrm{P}$ atoms, the immobile $\mathrm{B}$ atoms could be contained in binary or ternary precipitates and/or clusters. When dopants are activated in the Si crystal, they are ionized and occupy substitutional sites. Since B is a $p$-type dopant and $\mathrm{P}$ is a $n$-type dopant, attractive electrostatic interactions can exist between the two species depending on their concentrations. Considering the remark i) an additional term describing an extra driving force for $\mathrm{P}$ diffusion has to be inserted in the diffusion equation in order to simulate the $\mathrm{P}$ diffusion. The remarks ii) and iii) show that $\mathrm{P}$ atoms are interacting preferentially with the immobile B atoms than with the mobile B atoms. Especially, remark iii) shows that the extra driving force on the $\mathrm{P}$ diffusion cannot be the gradient of electric field between the $\mathrm{B}$ and $\mathrm{P}$ activated species, since if there is no concentration gradient in the mobile $\mathrm{B}$ distribution, the gradient of electric field should favor a flat $\mathrm{P}$ profile instead of uphill diffusion. 


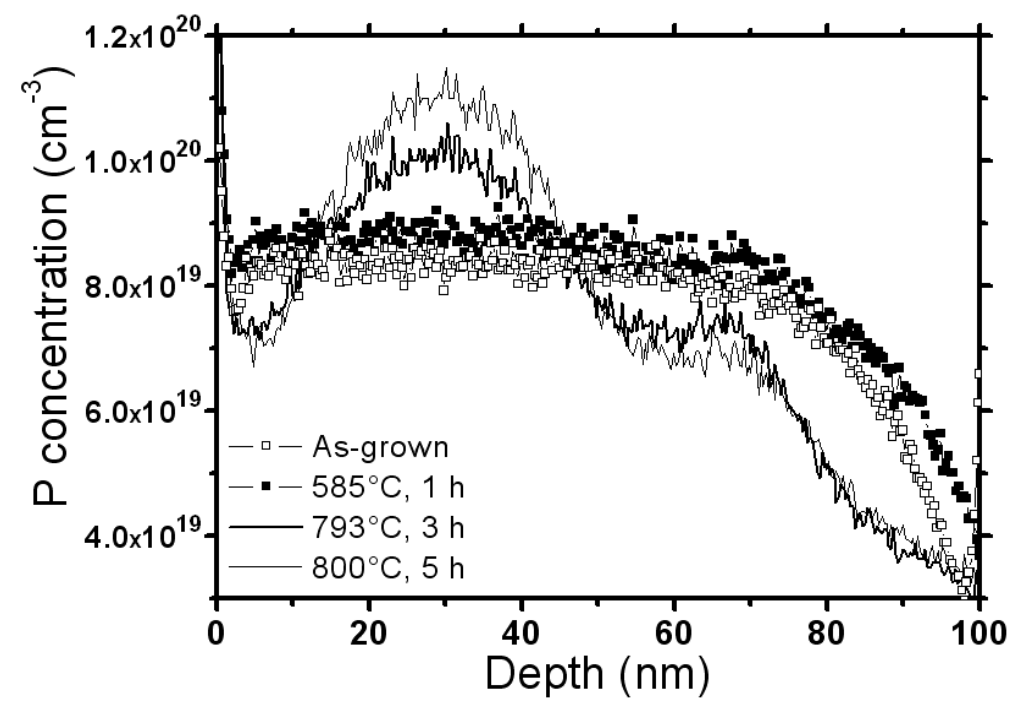

Fig. 5. SIMS profiles of $P$ measured in the sample after different heat treatments.

This supports the idea that in our experiments the $\mathrm{P}$ diffusion is driven by the chemical interactions between $\mathrm{P}$ and $\mathrm{B}$ atoms. It is then necessary to express the chemical potential of $\mathrm{P}$ as a function of the $\mathrm{B}$ concentration in order to simulate the uphill diffusion of $\mathrm{P}$. Describing the system as a regular ternary solution made of $\mathrm{Si}, \mathrm{B}$ and $\mathrm{P}$ atoms, the chemical potential of the $\mathrm{P}$ atoms $\left(\mu_{P}\right)$ can be written:

$$
\begin{aligned}
& \mu_{P}=k T \ln X_{P}+X_{S i}\left(X_{S i}+X_{B}\right) V^{S i P}+X_{B}\left(X_{B}+X_{S i}\right) V^{P B}-X_{B} X_{S i} V^{B S i} \\
& \text { with } V^{i j}=\varepsilon^{i j}-\frac{1}{2}\left(\varepsilon^{i i}+\varepsilon^{j j}\right) .
\end{aligned}
$$

$X_{i}$ is the atomic percentage of the element $\mathrm{i}$ in the solution, and $\varepsilon^{i j}<0$ is the pair interaction energy of the two elements $\mathrm{i}$ and $\mathrm{j} . V^{i j}$ describes the nature of the interactions between the elements $\mathrm{i}$ and $\mathrm{j}$ : if $V^{i j}>0$ the interactions are repulsive, if $V^{i j}<0$ the interactions are attractive. In view of the concentration of $\mathrm{B}$ and $\mathrm{P}$, one can consider that $X_{S i} \rightarrow 1$ and that $\left(1+X_{B}\right) \sim 1$, giving:

$$
\mu_{P} \approx k T \ln X_{P}+V^{S i P}+X_{B}\left(V^{P B}-V^{B S i}\right)=k T \ln X_{P}+V^{S i P}+X_{B} \Delta V .
$$

The first term in eq. 5 corresponds to the usual driving force of diffusion in the Fick equations [18], while the two other terms can be used for the definition of an extra driving force using the Nernst Einstein equation [18]. The flux of $\mathrm{P}$ atoms is then expressed as:

$$
J=-D_{P} \nabla C_{P}-C_{P} D_{P} \frac{\Delta V}{k T} \nabla X_{B} \text { with } \Delta V=\varepsilon^{P B}-\varepsilon^{B S i}+\frac{1}{2}\left(\varepsilon^{S i S i}-\varepsilon^{P P}\right) .
$$

$C_{P}$ is the $\mathrm{P}$ concentration and $D_{P}$ is the diffusion coefficient of $\mathrm{P}$. We used eq. 6 to simulate the diffusion of the $\mathrm{P}$ atoms in the crystallized Si matrix during a two hours annealing at $800{ }^{\circ} \mathrm{C}$, using the SIMS profile measured after annealing for $3 \mathrm{~h}$ at $793{ }^{\circ} \mathrm{C}$ as the initial $\mathrm{P}$ distribution, and the profile measured after annealing for $5 \mathrm{~h}$ at $800{ }^{\circ} \mathrm{C}$ as the final $\mathrm{P}$ distribution (fig. 5). During the simulation, the distribution of B was kept constant and equal to the SIMS profile measured after annealing at $800{ }^{\circ} \mathrm{C}$ for 5 hours (fig. 6). 


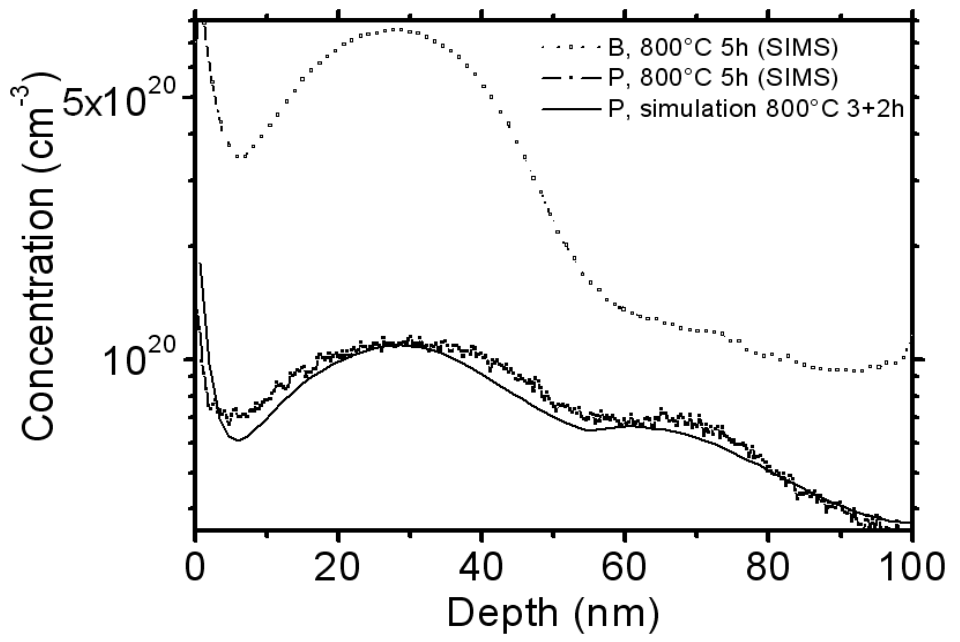

Fig. 6. SIMS profiles of B and $\mathrm{P}$ measured in the sample after annealing at $800^{\circ} \mathrm{C}$ for 5 hours, and the $\mathrm{P}$ profile simulated with $D_{g}=3.38 \times 10^{-17} \mathrm{~cm}^{2} \mathrm{~s}^{-1}, D_{g b}=$ $1.1 \times 10^{-13} \mathrm{~cm}^{2} \mathrm{~s}^{-1}$ and $\Delta V \sim$ $6.94 \mathrm{eV}$.

The simulation was performed in 2 dimensions (2D) following the Fisher model [19], in a similar way we previously simulated the B diffusion [15]. At the end of the simulation, the $2 \mathrm{D}$ distribution is converted to a 1D distribution to be compared to the experimental profile used as the final $\mathrm{P}$ distribution. According to the Fisher model, the parameters of the simulation are the lateral size of the grains $(l)$, the lateral size of the GBs $(\delta)$, and the P diffusion coefficients in the grains $\left(D_{g}\right)$ and in the GBs $\left(D_{g b}\right)$. We have also in our case the parameter $\Delta V$ that is related to the P-B interactions. We set $l=50 \mathrm{~nm}$ and $\delta=0.5 \mathrm{~nm}$ [20]. Since we simulate diffusion in grains and in GBs, several diffusion conditions can be investigated. For example, we can use eq. 6 only in the grains and use the conventional Fick equation (first term of eq. 6) in the GBs, and vice versa. The case of diffusion in the grains only or in the GBs only can be also investigated, and the effect of different combinations of diffusion coefficient values can be studied. The simulations have shown that i) $\mathrm{P}$ must diffuse in the grains in order to fit the experimental profile, i.e. the $\mathrm{P}$ diffusion uses the type $B$ kinetic regime at $800{ }^{\circ} \mathrm{C}$; ii) if the P-B interaction is taken into account in the GBs only and not in the grains, there is not enough material in the GBs in order to fit the experimental profile, i.e. the chemical attraction between $\mathrm{P}$ and $\mathrm{B}$ atoms has to be effective both in the grains and in the GBs to match the experimental results; and iii) the experimental profile obtained after annealing for $5 \mathrm{~h}$ at $800{ }^{\circ} \mathrm{C}$ can be simulated with eq. 6 , using the experimental values of $D_{g}\left(=3.38 \times 10^{-17} \mathrm{~cm}^{2} \mathrm{~s}^{-1}\right)$ and $D_{g b}\left(=1.1 \times 10^{-13} \mathrm{~cm}^{2} \mathrm{~s}^{-1}\right)$ at $800{ }^{\circ} \mathrm{C}$ from ref. [18] and [21] with $\Delta V \sim-6.94 \pm 0.2 \mathrm{eV}$ (fig. 6). In order to observe $\mathrm{P}$ uphill diffusion, the $\mathrm{P}$ flux resulting from the second term in eq. 6 (extra driving force) has to be in the opposite direction of the flux resulting from the first term of the same equation (Fickian term). Consequently, $\Delta V$ must be negative. Since the Si cohesive energy is higher than the $\mathrm{P}$ cohesive energy we have $1 / 2\left(\varepsilon^{S i S i}-\varepsilon^{P P}\right)<0$. Thus $\Delta V<0$ means in our formalism (eq. 6) that the P-B bonding energy is stronger than the B-Si bonding energy, meaning that B "prefers" to be surrounded by $\mathrm{P}$ atoms instead of Si atoms. Atom-pair energies are usually lower than $2 \mathrm{eV}$. In consequence $6.94 \mathrm{eV}$ appears to be too high to be a realistic difference of chemical bond energies. However, one has to notice that the atomic interactions in eq. 4 are considered only as pair interactions. In order to be more rigorous, ternary interactions should be considered between the 3 species $\mathrm{Si}, \mathrm{B}$ and $\mathrm{P}$ in the expression of the chemical potential of the $\mathrm{P}$ atoms. Thus, the parameter $\Delta V$ could hold a different meaning in eq. 6 .

\section{Summary}

The redistribution of $\mathrm{P}$ and $\mathrm{B}$ atoms during the crystallization of an amorphous Si layer grown by LPCVD has been investigated. The crystallization follows the Avrami-Johnson-Mehl-Kolmogorov law with an Avrami $\mathrm{n}=4$. For temperatures higher than $\sim 600{ }^{\circ} \mathrm{C}$, the nucleation of the crystalline grains is homogeneous (located in the layer) and the growth of the grains is 3 dimensional. The total 
activation energy (nucleation and growth) is found to be $\sim 16.8 \pm 0.5 \mathrm{eV}$. For temperature higher than $600{ }^{\circ} \mathrm{C}$ the average size of the grains is $\sim 50 \pm 5 \mathrm{~nm}$.

The Si crystallization induces the formation of clusters containing B atoms (immobile), as well as a first redistribution of a fraction of the $\mathrm{B}$ atoms allowing for a sharp $p n$-junction. Part of the $\mathrm{B}$ migrates about $20 \mathrm{~nm}$ deeper in the sample, forming a shoulder in the initial profile with a maximum concentration of $\sim 2 \times 10^{20}$ at $\mathrm{cm}^{-3}$. Since the crystallization does not proceed with a single interface progressing from the surface to the $\mathrm{SiO}_{2}$ film, this redistribution is attributed to $\mathrm{B}$ diffusion in a-Si before and during crystallization. After the crystallization, B diffuses via the type $B$ kinetic regime in a poly-Si layer of $\sim 50 \mathrm{~nm}$ wide grains, until that the concentration of mobile $\mathrm{B}$ atoms is homogeneous in the layer.

The $\mathrm{P}$ distribution is not modified by the crystallization, but for temperatures higher than $750{ }^{\circ} \mathrm{C}$ $\mathrm{P}$ uphill diffusion is observed. The $\mathrm{P}$ distribution evolves from a quasi-homogeneous distribution to a Gaussian distribution located underneath the Gaussian distribution of immobile B atoms. This phenomenon can be simulated considering chemical interactions between $\mathrm{P}$ and $\mathrm{B}$ atoms both in the grains and in the grain boundaries.

The authors would like to acknowledge P. Fornara from STMicroelectronics (Rousset, France) for experimental support and for providing the samples, as well as K. Hoummada from the IM2NP (Marseille, France) for the XRD measurements.

\section{References}

[1] B. Yan, G. Yue, J. M. Owens, J. Yang and S. Guha: Appl. Phys. Lett. Vol. 85 (2004), p. 1925

[2] T. Ito, H. Fukushima and M. Yamaguchi: Jap. J. Appl. Phys. Vol. 42 (2003), p. 1526

[3] R. Bouchakour, V. Bidal, P. Candelier, R. Fournel, P. Gendrier, R. Laffont, P. Masson, J. Mirabel, A. P. J. Regnier, J. M. Mirabel and A. Regnier, patent EP1768189-A1, FR2891398A1 and US2007069278-A1 (2007).

[4] J. S. Williams, R. G. Elliman: Phys. Rev. Lett. Vol. 51 (1983), p. 1069

[5] G. L. Olson, J. A. Roth: Mat. Sci. Rep. Vol. 3 (1988), p. 1

[6] N. G. Rudawski, K. S. Jones, R. Gwilliam: Phys. Rev. Lett. Vol. 100 (2008), p. 165501

[7] D. D’Angelo, L. Romano, I. Crupi, E. Carria, V. Privitera, M. G. Grimaldi: Appl. Phys. Lett. Vol. 93 (2008), p. 231901

[8] W. Barvosa-Carter, M. J. Aziz, A.-V. Phan, T. Kaplan, L. J. Gray:J . Appl. Phys. Vol. 96 (2004), p. 5462

[9] B. J. Pawlak, R. Duffy, T. Janssens, W. Vandervorst, K. Maex, A. J. Smith, N. E. B. Cowern, T. Dao, Y. Tamminga: Appl. Phys. Lett. Vol. 87 (2005), p. 31915

[10] B. C. Johnson, J. C. McCallum: Phys. Rev. B Vol. 76 (2007), p. 45216

[11] J. C. McCallum: Nucl. Inst. Meth. Phys. Res. B Vol. 148 (1999), p. 350

[8] M. Aboy, L. Pelaz, P. López, E. Bruno, S. Mirabella, E. Napolitani: Mat. Sci. Eng. B Vol. 154155 (2008), p. 247

[9] M. Aboy, L. Pelaz, P. López, L. A. Marqués, R. Duffy, V. C. Venezia: Apply. Phys. Lett. Vol. 88 (2006), p. 191917

[10] D. V. Ragone: Thermodynamics of Materials, volume 2 (John Wiley and Sons, 1995).

[11] J. Farjas, C. Rath, P. Roura, P. Roca I Cabarrocas: App. Surf. Sci. Vol. 238 (2004), p. 165

[12] R. Bisaro, J. Margariño, K. Zellama, S. Squelard, P. Germain and J. F. Morhange: Phys. Rev. B Vol. 31 (1985), p. 3568 
[13] J. R. A. Carlson, J.-E. Sundgren, L. D. Madsen, X.-H. Li, H. T. G. Hentzell: Thin Solid Films Vol. 300 (1997), p. 51

[14] C. Spinella, S. Lombardo, F. Priolo: J. Appl. Phys. Vol. 84 (1998), p. 5383

[15] A. Portavoce, R. Simola, D. Mangelinck, J. Bernardini and P. Fornara: Diffusion and Defect Data Vol. 264 (2007), p. 33

[16] R. Duffy, V.C. Venezia, A. Heringa, B.J. Pawlak, M.J.P. Hopstaken, G.C.J Maas, Y. Tamminga, T. Dao, F. Roozeboom, L. Pelaz: Appl. Phys. Lett. Vol. 84 (2004), p. 4283

[17] Binary Alloy Phase Diagrams (ASM International, 1996).

[18] P. Pichler: Intrinsic Point Defects, Impurities, and Their Diffusion in Silicon (SpringerVerlag/Wien, 2004).

[19] J.C. Fisher: J. Appl. Phys. Vol. 22 (1951), p. 74

[20] Y. Mishin, C. Herzig, J. Bernardini and W. Gust: International Mat. Rev. Vol. 42 (1997), p. 155

[21] K. Sakamoto, K. Nishi, T. Yamaji, T. Miyoshi and S. Ushio: J. Electrochem. Soc. Vol. 132 (1985), p. 2457 


\section{Diffusion in Materials - DIMAT2008}

doi:10.4028/www.scientific.net/DDF.289-292

\section{Atom Redistribution during co-Doped Amorphous Silicon Crystallization}

doi:10.4028/www.scientific.net/DDF.289-292.329

\section{References}

[1] B. Yan, G. Yue, J. M. Owens, J. Yang and S. Guha: Appl. Phys. Lett. Vol. 85 (2004), p. 1925

doi:10.1063/1.1790072

[2] T. Ito, H. Fukushima and M. Yamaguchi: Jap. J. Appl. Phys. Vol. 42 (2003), p. 1526 doi:10.1143/JJAP.42.1526

[3] R. Bouchakour, V. Bidal, P. Candelier, R. Fournel, P. Gendrier, R. Laffont, P. Masson, J. Mirabel, A. P. J. Regnier, J. M. Mirabel and A. Regnier, patent EP1768189-A1, FR2891398-A1 and US2007069278-A1 (2007).

[4] J. S. Williams, R. G. Elliman: Phys. Rev. Lett. Vol. 51 (1983), p. 1069 doi:10.1103/PhysRevLett.51.1069

[5] G. L. Olson, J. A. Roth: Mat. Sci. Rep. Vol. 3 (1988), p. 1 doi:10.1016/S0920-2307(88)80005-7

[6] N. G. Rudawski, K. S. Jones, R. Gwilliam: Phys. Rev. Lett. Vol. 100 (2008), p. 165501 doi:10.1103/PhysRevLett.100.165501

PMid:18518213

[7] D. D’Angelo, L. Romano, I. Crupi, E. Carria, V. Privitera, M. G. Grimaldi: Appl. Phys. Lett. Vol. 93 (2008), p. 231901

doi:10.1063/1.3036899

[8] W. Barvosa-Carter, M. J. Aziz, A.-V. Phan, T. Kaplan, L. J. Gray:J . Appl. Phys. Vol. 96 (2004), p. 5462

doi:10.1063/1.1790580

[9] B. J. Pawlak, R. Duffy, T. Janssens, W. Vandervorst, K. Maex, A. J. Smith, N. E. B. Cowern, T. Dao, Y. Tamminga: Appl. Phys. Lett. Vol. 87 (2005), p. 31915 doi:10.1063/1.1997276

[10] B. C. Johnson, J. C. McCallum: Phys. Rev. B Vol. 76 (2007), p. 45216 doi:10.1103/PhysRevB.76.045216

[11] J. C. McCallum: Nucl. Inst. Meth. Phys. Res. B Vol. 148 (1999), p. 350 [8] M. Aboy, L. Pelaz, P. López, E. Bruno, S. Mirabella, E. Napolitani: Mat. Sci. Eng. B Vol. 154-155 (2008), p. 247 [9] M. Aboy, L. Pelaz, P. López, L. A. Marqués, R. Duffy, V. C. Venezia: 
Apply. Phys. Lett. Vol. 88 (2006), p. 191917 [10] D. V. Ragone: Thermodynamics of Materials, volume 2 (John Wiley and Sons, 1995).

[11] J. Farjas, C. Rath, P. Roura, P. Roca I Cabarrocas: App. Surf. Sci. Vol. 238 (2004), p. 165

[12] R. Bisaro, J. Margariño, K. Zellama, S. Squelard, P. Germain and J. F. Morhange: Phys. Rev. B Vol. 31 (1985), p. 3568

doi:10.1103/PhysRevB.31.3568

[13] J. R. A. Carlson, J.-E. Sundgren, L. D. Madsen, X.-H. Li, H. T. G. Hentzell: Thin Solid Films Vol. 300 (1997), p. 51

doi:10.1016/S0040-6090(96)09499-0

[14] C. Spinella, S. Lombardo, F. Priolo: J. Appl. Phys. Vol. 84 (1998), p. 5383 doi:10.1063/1.368873

[15] A. Portavoce, R. Simola, D. Mangelinck, J. Bernardini and P. Fornara: Diffusion and Defect Data Vol. 264 (2007), p. 33

doi:10.4028/www.scientific.net/DDF.264.33

[16] R. Duffy, V.C. Venezia, A. Heringa, B.J. Pawlak, M.J.P. Hopstaken, G.C.J Maas, Y. Tamminga, T. Dao, F. Roozeboom, L. Pelaz: Appl. Phys. Lett. Vol. 84 (2004), p. 4283 doi:10.1063/1.1751225

[17] Binary Alloy Phase Diagrams (ASM International, 1996).

[18] P. Pichler: Intrinsic Point Defects, Impurities, and Their Diffusion in Silicon (SpringerVerlag/Wien, 2004).

[19] J.C. Fisher: J. Appl. Phys. Vol. 22 (1951), p. 74

doi:10.1063/1.1699825

[20] Y. Mishin, C. Herzig, J. Bernardini and W. Gust: International Mat. Rev. Vol. 42 (1997), p. 155

[21] K. Sakamoto, K. Nishi, T. Yamaji, T. Miyoshi and S. Ushio: J. Electrochem. Soc. Vol. 132 (1985), p. 2457

doi:10.1149/1.2113599 